\title{
TWO RED CROSS MEETINGS
}

Switzerland.-On 27 and 28 April, Miss Anny Pfirter, head of the Nursing Personnel Service, was invited by the Swiss Red Cross to attend a conference of nursing schools recognized by this National Society, which was held in Bern. Nearly 250 principals and instructors from the nursing schools attended the discussions, which were followed by group working sessions. The evolution of the nursing profession, in the light of modern technology and science, was the main subject of discussions.

Germany.-In Bremen from 11 to 14 May, the German Red Cross Nurses' Associations in the Federal Republic of Germany held a conference. All the principals of these establishments attended the conference accompanied by delegations of nurses.

The local political, medical and Red Cross authorities were also represented there.

Several persons spoke. Miss Pfirter took the floor firstly to convey the ICRC's best wishes. She then drew a parallel between Henry Dunant, founder of the Red Cross, and Florence Nightingale, the 150th anniversary of whose birth was being celebrated that day, as well as the fiftieth anniversary of the first awarding of the medal that bears her name.

The pupils of the Bremen Nursing School read and commented on the principles of the Red Cross. 